\title{
Mechanical Harvesting Increases Leaf and Stem Debris in Loads of Mechanically Harvested Citrus Fruit
}

\author{
Timothy M. Spann ${ }^{1}$ \\ University of Florida, Horticultural Sciences Department, Citrus Research \\ and Education Center, 700 Experiment Station Road, Lake Alfred, FL 33850
}

\author{
Michelle D. Danyluk \\ University of Florida, Food Science and Human Nutrition Department, \\ Citrus Research and Education Center, 700 Experiment Station Road, Lake \\ Alfred, FL 33850
}

Additional index words. sweet orange, Citrus sinensis, canopy shaker, mechanized harvest

\begin{abstract}
The adoption of mechanical harvesting for processing oranges is a major objective of the Florida citrus industry. A number of issues have slowed the adoption of this new technology, including the observation that the amount of leaves, stems, and dead branches (collectively termed "debris") is greater in mechanically harvested than in hand-harvested loads of fruit. This debris increases transportation and processing costs. The objective of this research was to determine the amount and types of debris in mechanically harvested loads of sweet oranges compared with hand-harvested controls. Mechanical harvesting was found to increase the amount of debris per load of fruit by as much as $250 \%$ compared with hand-harvested fruit. This translates into $\approx 108 \mathrm{~kg}$ of debris compared with $71 \mathrm{~kg}$ (fresh weight) per $27 \mathrm{t}$ load for mechanically harvested and hand-harvested fruit, respectively. Across harvesting method, leaves were the largest component of debris, accounting for $\approx \mathbf{6 0 \%}$ of total debris, small stems (less than $5 \mathrm{~mm}$ diameter) accounted for $\approx 35 \%$, and the remaining $5 \%$ was large stems (greater than $5 \mathrm{~mm}$ diameter). In addition, the amount of sand on the surface of mechanically harvested fruit that was picked up from the orchard floor was found to be up to 10 times greater compared with hand-harvested controls. Engineers developing debris elimination systems for mechanical harvesting systems can use the data from this study to determine the performance requirements of their systems. The data are also useful for economic analyses of the costs of mechanical harvesting.
\end{abstract}

Citrus is a crop of great economic importance to the state of Florida. In the 2007-2008 season, 203.8 million $40-\mathrm{kg}$ boxes of fruit were harvested from $\approx 225,000$ ha with a farm-gate value of $\approx \$ 1$ billion and a total economic impact of $\$ 9$ billion (Florida Agricultural Statistics Service, 2009). Harvesting represents a significant portion of the cost of producing citrus, accounting for as much as $50 \%$ of total production costs (Muraro, 2009). In addition, the citrus industry is reliant on 20,000 to 25,000 seasonal migrant laborers for hand harvesting (Spreen et al., 2006). This labor source is subject to unpredictable fluctuations as a result of competition from other industries and immigration regulations. Strong competition for labor from the booming construction industry from 2002 to 2006 reduced labor availability and increased labor costs for harvesting (Roka et al., 2009). In addition, recent immigration reform efforts have increased concerns about labor availability (Kates, 2006; Sparks, 2008). Ever increasing global competition, particularly from Brazil

Received for publication 27 Apr. 2010. Accepted for publication 23 May 2010.

${ }^{1}$ To whom reprint requests should be addressed; e-mailspann@ufl.edu. and China, dictates that Florida citrus growers develop cost-saving technologies. A cost analysis by Muraro and Spreen (2003) found that during the 2000-2001 harvest season, Brazilian citrus growers were able to deliver frozen concentrated orange juice to the port of Tampa, FL, for only $\$ 0.0757$ more per pound solids than Florida growers. For these reasons, Florida has been working to develop mechanical harvesting technology since the 1950s (Whitney, 1995), and these efforts were renewed in earnest in 1995 when the Florida Department of Citrus commissioned the Harvest Research Advisory Council (Florida Department of Citrus, 2010).

In traditional hand harvesting of citrus, fruit are picked and placed into picking sacks; the fruit are dumped from the picking sacks into 10-box (40 kg per box) field tubs, which are mechanically hoisted and dumped into a field transport vehicle commonly referred to as a "goat." The goat transfers the fruit to open-topped semitrailers (27 t capacity) for transport to the processing plant. Currently, two mechanical harvesting systems are in use in Florida, the Oxbo 3220 continuous travel canopy shake and catch harvesting system and the Oxbo 3210 tractor powered continuous travel canopy shake harvester (Fig. 1; Oxbo International Corp., Clear Lake, WI).
The systems use the existing fruit hauling equipment to minimize the need for additional investment in new equipment. The 3220 system operates as a pair of machines, one on each side of the tree, and harvests fruit using a series of tines $(\approx 2 \mathrm{~m}$ long $)$ that penetrate the canopy and vibrate at an operator-determined frequency for optimal fruit removal. Most of the removed fruit are caught on a catch frame and conveyed into a goat and then transferred to semitrailers for transport to the processing plant. The machines may be fitted with an optional de-stemmer placed at the end of the conveyor belt as the fruit enter the goat. The 3210 harvester uses the same canopy shaker mechanism as the 3220 but is pulled behind and powered by a tractor. The 3210-harvested fruit drop to the ground and are manually collected. The manually collected fruit are then handled similarly to hand-harvested fruit.

Adoption of mechanical harvesting technology has been slow. In the 2008-2009 harvest season, just less than 15,000 ha $(7 \%$ of total acreage) of citrus were mechanically harvested in Florida (Florida Department of Citrus, 2009). Several issues have contributed to this slow adoption, including issues related to harvesting late-season 'Valencia' oranges, concerns about the effects of mechanical harvesting on tree health, and processor concerns about increases in the quantity of debris mixed with mechanically harvested fruit (Roka et al., 2009).

Citrus growers have been concerned about the damage the mechanical harvester tines cause to their trees as they rake the fruit from the canopy. This action can remove what appears to be a large number of leaves, small twigs, and an occasional large branch (Fig. 2), particularly the first time an orchard is mechanically harvested or after severe stem dieback (e.g., after a freeze or hurricane). Studies following the same mechanically harvested trees over multiple harvest seasons found no detrimental effects of this damage on tree health, return bloom, or yield compared with trees that were hand harvested during the same time (Buker et al., 2009; Li and Syvertsen, 2005). However, orange juice processors are concerned that this removal of leaves, twigs, and branches is resulting in more debris being delivered to the processing plants. Any increase in debris entering the processing plant increases operational costs as a result of machine damage, labor to remove the debris, and disposal costs. Debris, commonly referred to as trash, is a widely occurring problem of mechanical fruit and vegetable harvesting as evidenced by the number of research reports on trash removal from mechanically harvested crops (Clayton and Whittemore, 1971; Esch and Marshall, 1987; Lenker and Nascimento, 1982; Marshall, 1984; Mullins, 2000; Patil et al., 2009). Despite this, it appears that very little work has been done to quantify and describe the debris associated with mechanical harvesting (Tambosco et al., 1978). However, it is important to characterize the components in the debris to facilitate the development of improved debris 
A

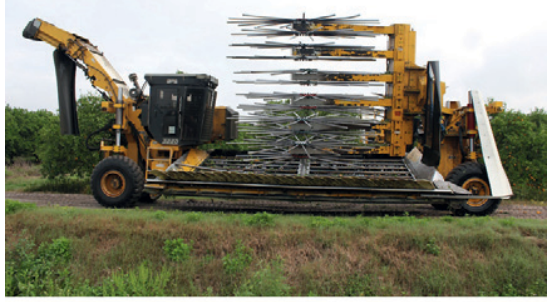

B

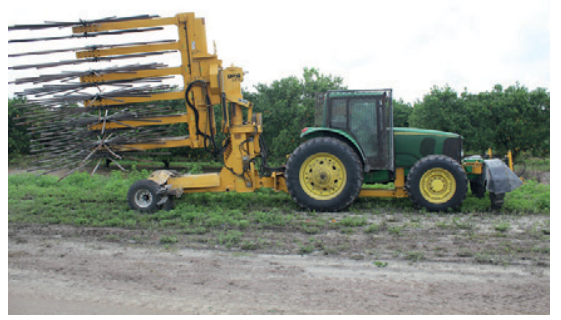

Fig. 1. Side view of the Oxbo 3220 continuous travel canopy shake and catch harvesting system (top) and the Oxbo 3210 tractor-powered continuous travel canopy shake harvester (bottom).

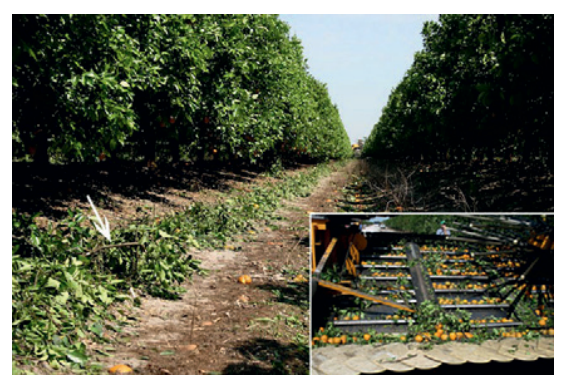

Fig. 2. Photograph showing some of the leaves and stems (debris) removed from the canopy during mechanical harvesting of citrus; note the large branch (arrow). Debris collected on the catch frame of the Oxbo 3220 continuous travel canopy shake and catch harvesting system (inset).

removal systems and to provide data for costbenefit analyses of mechanical harvesting systems.

The purpose of this study was to determine the amount of debris in loads of handharvested and mechanically harvested sweet oranges and to characterize this debris.

\section{Materials and Methods}

Harvesting systems. Debris samples were collected from three different harvest systems: hand harvesting (control), continuous travel canopy shake and catch harvesting system (Model 3220), and tractor-powered continuous travel canopy shake harvester (Model 3210). Because of its large size, the 3220 harvester is most efficiently operated in large orchards (greater than $1000 \mathrm{ha}$ ) that have long rows of trees and is relatively difficult to move between orchards. The 3210 is much smaller and maneuverable and is generally operated in small orchards. These inherent differences required us to collect samples from the different harvesting systems in different orchards.

Orange orchards harvested. 'Valencia' and 'Hamlin' sweet oranges (Citrus sinensis) were harvested in two commercial orchards during the 2007-2008 and 2008-2009 harvest seasons, respectively. The same company owned both orchards so orchard care was similar among the locations. Both varieties were harvested from within a 400-ha orchard near Lake Wales, FL, and a 9000-ha orchard near Fort Basinger, FL. Model 3210 samples were collected from the smaller orchard near Lake Wales, and Model 3220 samples were collected from the large orchard near Fort Basinger. Hand-harvested 'Valencia' samples were collected from Lake Wales, and hand-harvested 'Hamlin' samples were collected from Fort Basinger. Within each of these orchards, trees were divided into blocks of a single variety and age. Blocks within the Lake Wales orchard were $\approx 30$ to 35 ha, whereas blocks in the Fort Basinger orchard were $\approx 60$ ha. Each block was considered a replication, and at least 15 fruit/ debris subsamples (described subsequently) were collected from within each block. Three blocks were sampled for each harvest method and variety. Because the different harvesting systems had to be sampled from different orchards, the sampled blocks were selected for similarity in tree age, size, spacing, and overall health to minimize variability resulting from these factors. All blocks had been mechanically harvested for at least the season immediately before sampling and in some cases had been harvested mechanically for multiple seasons.

During the 2007-2008 'Valencia' season, two 3220 harvesting machine pairs were operating in the Fort Basinger orchard, one with the optional de-stemmer and one without. Thus, for the 'Valencia' data, four total harvest methods were compared: hand, 3210, 3220 with de-stemmer, and 3220 without destemmer. Before the start of the 2008-2009 'Hamlin' harvest season, the 3220 system without the de-stemmer was retrofitted with a de-stemmer unit. Thus, for the 'Hamlin' data, three harvest methods were compared: hand, 3210, and 3220 with de-stemmer.

Sample collection. Because regardless of harvest method (hand versus mechanical), all harvested fruit ultimately make their way to the goat transport vehicle, we decided to collect samples as the fruit were transferred from the goat to the fruit trailer. Any debris mixed with the fruit at this point will be delivered to the processing plant.

Samples were collected by laying a wooden frame across the top of the fruit trailer and placing a plastic tub $\approx 90 \times 60 \times 20 \mathrm{~cm}$ (length $\times$ width $\times$ depth) on top of the wooden frame. Fruit and debris was collected in the tub as the load was transferred from the goat into the trailer. After the transfer of fruit was complete, any fruit and debris piled above the top of the sample bin were removed. Each full-loaded bin collected $\approx 70 \mathrm{~kg}$ of fruit and debris. Because there was a tendency for large, long branches to hit the side of the sampling bin and

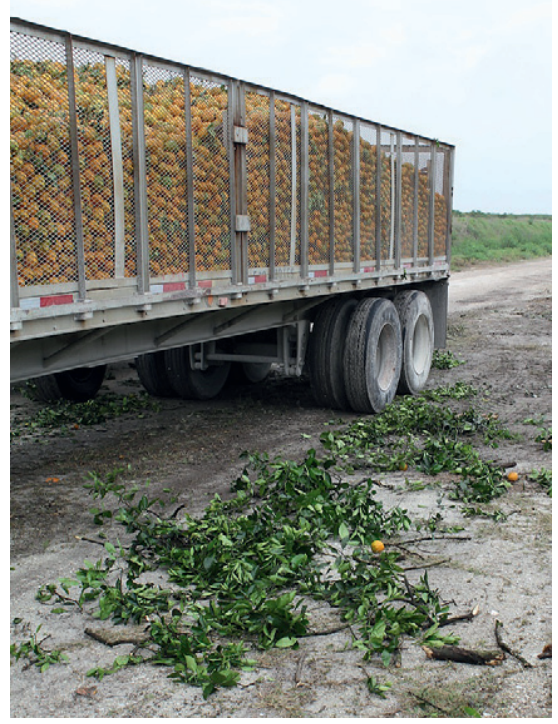

Fig. 3. Photograph showing a range of debris that was removed from a load of fruit harvested with the Oxbo 3220 mechanical harvesting system. Note the large branch in the lower right foreground.

bounce out, we probably underestimated this component.

All samples were weighed and the total weight of fruit and debris recorded. The fruit and debris (leaves and stems) were then separated by hand and the debris weighed. The weight of fruit per sample was calculated by subtracting the debris weight from the total sample weight. During sorting, 10 fruit were randomly selected and placed in a plastic bag for determination of sand accumulation on the fruit surface. The debris and fruit samples were taken back to the laboratory for further processing.

Debris processing. In the laboratory, the debris was separated into leaves, small stems (less than $5 \mathrm{~mm}$ diameter), and large stems (greater than $5 \mathrm{~mm}$ diameter). Each category of debris was weighed fresh, dried to a constant weight at $65{ }^{\circ} \mathrm{C}$, and the dry weight recorded. Although both harvesters and processors handle debris in its fresh state, the debris was dried to reduce variability across samples because time of day, rain or irrigation, and relative time during the harvest season can significantly affect stem and leaf fresh weight. To address this discrepancy, a total estimated fresh weight per $27 \mathrm{t}$ load was calculated for each harvest method by multiplying the total average fresh weight of debris per kilogram of fruit for a harvest method by 27,000 .

For surface sand contamination, the collected fruit samples described previously were hand washed with tap water using up to $2 \mathrm{~L}$. The surface area of each of the 10 fruit per sample was calculated by measuring their diameter and calculating surface area assuming the fruit were spheres. The wash water was allowed to settle for $24 \mathrm{~h}$ and was filtered through one sheet of pre-weighed filter paper $(11.0 \mathrm{~cm}$ diameter; Fisherbrand Qualitative 
Q8, course; Fisher Scientific, Pittsburgh, PA) with the use of a vacuum pump (Barnant Company Vacuum Pressure station, Barrington, IL). Filter paper and sand were placed into an aluminum weighing dish and dried in a drying oven at $80^{\circ} \mathrm{C}$ for $24 \mathrm{~h}$. The dry filter paper and sand were weighed and the mass of sand per unit of fruit surface area was calculated. An incalculable quantity of sand was lost during sampling as a result of fruit handling at each step of the process, so our method was underestimating the quantity of this debris component. Therefore, sand data were only collected for 'Valencia' fruit.

Statistical analysis. Analysis of variance for a completely randomized design was performed for the amount of debris by type (leaves, small stems, large stems, and sand) using Prism 5.0 (GraphPad Software, La Jolla, $C A)$ followed by means separation by Tukey's honestly significant difference $(P=0.05)$. Per-

Table 1. Amount of individual debris components and total debris ( $\mathrm{g}$ debris $/ \mathrm{kg}$ fruit) for samples collected from hand-harvested fruit and three different mechanical harvesters during the 2007-2008 'Valencia' harvest season.

\begin{tabular}{|c|c|c|c|c|c|c|}
\hline \multirow[b]{3}{*}{ Harvest method ${ }^{2}$} & \multicolumn{3}{|c|}{ Debris component } & \multirow{3}{*}{$\begin{array}{c}\text { Total } \\
\text { debris }\end{array}$} & \multirow{3}{*}{$\begin{array}{l}\text { Estimated debris } \\
\text { per load (kg } \\
\text { fresh weight })^{\mathrm{x}}\end{array}$} & \multirow{3}{*}{$\begin{array}{c}\text { Sand } \\
\left(\mathrm{mg} \cdot \mathrm{cm}^{-2}\right)\end{array}$} \\
\hline & Leaves & Small stems & Large stems & & & \\
\hline & \multicolumn{3}{|c|}{ (g dry weight $/ \mathrm{kg}$ fruit) } & & & \\
\hline Hand harvest & $0.67 \mathrm{~b}^{\mathrm{y}}$ & $0.44 \mathrm{c}$ & $0.02 \mathrm{~b}$ & $1.12 \mathrm{~b}$ & $71.7 \mathrm{c}$ & $0.038 \mathrm{~b}$ \\
\hline Oxbo 3210 & $1.62 \mathrm{a}$ & $1.23 \mathrm{a}$ & $0.15 \mathrm{a}$ & $3.00 \mathrm{a}$ & $137.6 \mathrm{a}$ & $0.417 \mathrm{a}$ \\
\hline $\begin{array}{l}\text { Oxbo } 3220 \text { with } \\
\text { de-stemmer }\end{array}$ & $0.86 \mathrm{~b}$ & $0.76 \mathrm{~b}$ & $0.20 \mathrm{a}$ & $1.82 \mathrm{~b}$ & $104.4 \mathrm{~b}$ & $0.058 \mathrm{~b}$ \\
\hline Oxbo 3220 without & $0.70 \mathrm{~b}$ & $0.69 \mathrm{bc}$ & $0.09 \mathrm{ab}$ & $1.49 \mathrm{~b}$ & $94.6 \mathrm{~b}$ & $0.018 \mathrm{~b}$ \\
\hline
\end{tabular}

de-stemmer

Percent of total debris

$\begin{array}{llll}\text { Hand harvest } & 60 \mathrm{a} & 39 \mathrm{~b} & 1 \mathrm{~b} \\ \text { Oxbo 3210 } & 54 \mathrm{~b} & 41 \mathrm{~b} & 5 \mathrm{ab} \\ \begin{array}{l}\text { Oxbo 3220 with } \\ \text { de-stemmer }\end{array} & 47 \mathrm{c} & 42 \mathrm{~b} & 11 \mathrm{a} \\ \begin{array}{l}\text { Oxbo 3220 without } \\ \text { O }\end{array} & 47 \mathrm{c} & 46 \mathrm{a} & 6 \mathrm{ab}\end{array}$

de-stemmer

${ }^{\mathrm{z}}$ Fruit were harvested by one of four methods: hand harvest, Oxbo 3210 tractor-powered continuous travel canopy shake harvester, or Oxbo 3220 continuous travel canopy shake and catch harvesting system with or without optional de-stemmer.

${ }^{y}$ Values within columns with different letters are significantly different $(P=0.05)$ using Tukey's honestly significant difference.

${ }^{\mathrm{x}}$ An estimation of the total fresh weight of debris per $27 \mathrm{t}$ semitrailer load that would actually be hauled and delivered to the processing plant.

Table 2. Amount of individual debris components and total debris ( $\mathrm{g}$ debris $/ \mathrm{kg}$ fruit) for samples collected from hand-harvested fruit and two different mechanical harvesters during the 2008-2009 'Hamlin' harvest season.

\begin{tabular}{|c|c|c|c|c|c|}
\hline \multirow[b]{3}{*}{ Harvest method ${ }^{\mathrm{z}}$} & \multicolumn{3}{|c|}{ Debris component } & \multirow{2}{*}{$\begin{array}{l}\text { Total } \\
\text { debris }\end{array}$} & \multirow{3}{*}{$\begin{array}{c}\text { Estimated debris } \\
\text { per load }(\mathrm{kg} \\
\text { fresh weight })^{\mathrm{x}}\end{array}$} \\
\hline & Leaves & Small stems & Large stems & & \\
\hline & \multicolumn{4}{|c|}{ (g dry weight/kg fruit) } & \\
\hline Hand harvest & $0.76 b^{y}$ & $0.45 \mathrm{~b}$ & $0.00 \mathrm{~b}$ & $1.22 \mathrm{~b}$ & $72.7 \mathrm{~b}$ \\
\hline Oxbo 3210 & $1.43 \mathrm{a}$ & $0.90 \mathrm{a}$ & $0.16 \mathrm{a}$ & $2.50 \mathrm{a}$ & $117.7 \mathrm{a}$ \\
\hline Oxbo 3220 & $0.92 \mathrm{~b}$ & $0.72 \mathrm{ab}$ & $0.03 \mathrm{~b}$ & $1.45 \mathrm{~b}$ & $89.6 \mathrm{~b}$ \\
\hline
\end{tabular}

Percent of total debris

$\begin{array}{llll}\text { Hand harvest } & 65 \mathrm{~b} & 35 \mathrm{~b} & 0 \mathrm{~b} \\ \text { Oxbo } 3210 & 57 \mathrm{~b} & 36 \mathrm{~b} & 7 \mathrm{a} \\ \text { Oxbo } 3220 & 70 \mathrm{a} & 57 \mathrm{a} & 3 \mathrm{a}\end{array}$

${ }^{\mathrm{z}}$ Fruit were harvested by one of three methods: hand harvest, Oxbo 3210 tractor-powered continuous travel canopy shake harvester, or Oxbo 3220 continuous travel canopy shake and catch harvesting system with optional de-stemmer.

${ }^{y}$ Values within columns with different letters are significantly different $(P=0.05)$ using Tukey's honestly significant difference.

${ }^{x}$ An estimation of the total fresh weight of debris per $27 \mathrm{t}$ semitrailer load that would actually be hauled and delivered to the processing plant. harvest systems and generally accounted for not more than $5 \%$ of total debris. No significant differences were found in the amount of any debris type for fruit harvested with the 3220 systems with or without the optional destemmer (Table 1). Sand was found to be approximately an order of magnitude greater for 'Valencia' fruit harvested by the 3210 system compared with either hand harvesting or the 3220 system (Table 1 ).

\section{Discussion}

Florida citrus processors have observed an increase in the total amount of debris in loads of mechanically harvested sweet oranges compared with hand harvesting. Our data support these observations and indicate that the total debris from mechanical harvesting is increased from $20 \%$ to more than $250 \%$ depending on harvesting system and variety. Fruit harvested with the tractor-drawn 3210 system had the most debris of any harvest system. This is counterintuitive because fruit harvested by this system are dropped to the ground and picked up by hand and, therefore, should be very clean. However, hand labor crews are usually paid per box of fruit harvested, giving them an incentive to move quickly. Thus, many laborers working with the 3210 system will tend to sweep fruit from the orchard floor into their picking sacks rather than picking up individual pieces of fruit and in so doing collect large quantities of debris. In a worst-case scenario, this equated to nearly $140 \mathrm{~kg}$ per trailer load (equivalent to more than three $40-\mathrm{kg}$ boxes of fruit) of debris being hauled to the processing plant. In addition, mechanical harvesting tended to shift the relative proportion of the different types of debris, generally reducing the percentage of leaves and increasing the percentage of small and large stems.

Citrus processors have indicated that large stems (greater than $2 \mathrm{~cm}$ diameter) and sand are the two most costly types of debris entering the processing plants (D. Crumbly, Citrus World, Inc., personal communication). Largediameter stems have the potential to jam or break equipment (conveyor belts, juice extractors) leading to costly repairs and temporary loss of processing capacity. A 2009 survey of Florida citrus processors estimated the total cost of equipment downtime and juice yield losses as a result of debris at nearly $\$ 0.098$ per $40-\mathrm{kg}$ box of fruit processed (F. Roka, personal communication). Assuming that the 15,000 ha of citrus mechanically harvested in 2008-2009 yielded the industry average of 1100 boxes/ha, this equates to $\approx \$ 1.65 \mathrm{~m}$ in debris-related costs industrywide. Large stems were rare in our samples possibly because our sampling method may have artificially selected against large stems. However, Figure 3 shows a sampling of the range of debris that can be commonly found in a load of mechanically harvested fruit.

Sand is particularly troubling in the processing plant because of its abrasive nature, and it can quickly wear out moving parts. In addition, it is difficult to filter from the final 
juice product; therefore, processing plants must use large volumes of water everyday to thoroughly wash fruit before juice extraction. The processors must then pay to dispose of the accumulated sand in landfills. Not surprising, we found that sand was greatest when fruit were harvested using the 3210 system, which drops fruit onto the ground. Thus, the fruit can accumulate large amounts of sand on their surface, particularly if the orchard floor is moist from dew, rain, or irrigation. These results are similar to those reported by Tambosco et al. (1978) for handcut and mechanically loaded sugar cane. They found that sugar cane that was hand cut and left in the row for mechanical loading had $3.2 \%$ more trash, primarily as a result of soil contamination, compared with combineharvested cane. The fact that our data showed an order of magnitude more sand in 3210harvested fruit, despite the likely underestimate resulting from sample handling, emphasizes the importance of this contaminant.

Mechanical harvesting of citrus fruit in Florida has been under development for more than 50 years, and it is viewed as a necessity going forward to allow Florida citrus growers to reduce costs and remain competitive in a global market. However, a number of issues have prevented its rapid adoption, including concerns by processors about leaf, stem, and sand debris in loads of harvested fruit. This study developed a data set defining the most common types of debris in loads of mechanically harvested citrus and quantified each of those debris types. These data will be useful for evaluating the costs and benefits of mechanical harvesting and will be very beneficial to agricultural engineers who are developing debris removal systems for mechanical harvesting machines. In addition, tree management practices that may prevent debris from entering the harvesting stream like tree pruning and the use of chemical abscission agents to aid in fruit removal and various factors that may influence debris quantities (e.g., tree age, harvester operating parameters) should be investigated.

\section{Literature Cited}

Buker, R.S., J.P. Syvertsen, J.K. Burns, F.M. Roka, W.M. Miller, M. Salyani, and G.K. Brown. 2009. Mechanical harvesting and tree health. Electronic Data Information Source HS961. Univ. FL, Gainesville, FL, 18 May 2010. $<$ http://edis.ifas.ufl.edu/pdffiles/HS/HS19900. pdf $>$.

Clayton, J.E. and H.D. Whittemore. 1971. Systems for cleaning immature tops and other trash from sugarcane. Proc. Intl. Soc. Sugarcane Technol. p. $73-78$.

Esch, T.A. and D.E. Marshall. 1987. Trash removal from mechanically harvested peppers. Trans. ASAE 30:893-898.

Florida Agricultural Statistics Service. 2009. Citrus Summary 2007-08. FL Dept. Agr. Consumer Serv., Tallahassee, FL.

Florida Department of Citrus. 2009. Mechanically harvested acres and boxes. 16 Apr. 2010. $<$ http:// citrusmh.ifas.ufl.edu/index.asp? $\mathrm{s}=2 \& \mathrm{p}=2>$.

Florida Department of Citrus. 2010. Harvesting research. 16 Apr. 2010. <http://www.fdocgrower. com/sr/harvestingresearch.php>.

Kates, W. 2006. The agricultural worker situation in Florida. Proc. Fla. State Hort. Soc. 119:2024.

Lenker, D.H. and D.F. Nascimento. 1982. Mechanical harvesting and cleaning of chili peppers. Trans. ASAE 25:42-46.

Li, K.-T. and J.P. Syvertsen. 2005. Mechanical harvesting has little effect on water status and leaf gas exchange in citrus trees. J. Amer. Soc. Hort. Sci. 130:661-666.

Marshall, D.E. 1984. Mechanized pepper harvesting and trash removal. Paper No. 584. Proc. Intl. Conf. on Harvest Mechanization of Fruit, Nut and Vegetable Harvesting Mechanization. ASABE, St. Joseph, MI.

Mullins, C.A. 2000. Mechanical harvest of 'White Half Runner' beans, plateau experiment station, 2000. 15 Apr. 2010. <http://bioengr.ag.utk.
edu/ExtProg/Vegetable/year/VegInitReport00/ vegetable_initiative_report.htm $>$.

Muraro, R.P. 2009. Estimated average picking, roadsiding and hauling charges for Florida citrus, 2008-09 season. 15 Apr. 2010. <http:// www.crec.ifas.ufl.edu/extension/economics/ pdf/Estimated_Average_Picking_2008-09.pdf $>$.

Muraro, R.P. and T.H. Spreen. 2003. Comparative marketing costs for FCOJ from Florida and Sao Paulo. Electronic Data Information Source FE363. Univ. FL, Gainesville, FL, 15 Apr. 2010. $<$ http://edis.ifas.ufl.edu/pdffiles/FE/FE36300. pdf $>$.

Patil, R., W.S. Lee, R. Shankar, and R. Ehsani. 2009. Detection and elimination of trash using machine vision and extended de-stemmer for a citrus canopy shaker and catch harvester. Paper No. FL09-129. Florida Section 2009 ASABE Annual Conference Meeting. ASABE, St. Joseph, MI.

Roka, F.M., J.K. Burns, J. Syvertsen, T. Spann, and B. Hyman. 2009. Improving the economic viability of Florida citrus by enhancing mechanical harvesting with the abscission agent CMNP. Univ. FL, Inst. Food Agr. Sci., Gainesville, FL. 16 Apr. 2010. <http://citrusmh.ifas. ufl.edu/pdf/db/abscission_white_paper_040609. pdf $>$.

Sparks, M. 2008. The state of the Florida citrus industry. The Buzz. Citrus Industry 89:6.

Spreen, T.H., R.E. Barber, M.G. Brown, A.G. Hodges, J.C. Malugen, W.D. Mulkey, R.P. Muraro, R.P. Norberg, M. Rahmani, F.M. Roka, and R.E. Rouse. 2006. An economic assessment of the future prospects for the Florida citrus industry. Univ. FL., Inst. Food Agr. Sci., Gainesville, FL. 18 May 2010. $<\mathrm{http}: / /$ www.floridajuice.ifas.ufl.edu/pubs/Econ Assessment.pdf $>$.

Tambosco, N., J.P.B. Teixeira, L. Geraldi Filho, E.J. Ustulin, J.L. de, P. Henrique, O. Alonso, W.J. Correa, L.R. Franceschi, R.N. Geraldi, J.C. Salata, and G.E. Serra. 1978. Trash in mechanical and manual harvesting of sugar cane. Sugar J. 6:21-23.

Whitney, J.D. 1995. A review of citrus harvesting in Florida. Proc. Citrus Eng. Conf., Univ. of FL, Citrus Res. Educ. Ctr., Lake Alfred, FL3360. 